\title{
Implementation of Artificial Intelligence in Agriculture: A Review for CMS Optimization
}

\author{
Takudzwa Fadziso \\ Institute of Lifelong Learning and Development Studies, Chinhoyi University of Technology, ZIMBABWE \\ *Email for Correspondence: fadziso1986@ gmail.com
}

\begin{abstract}
Agriculture has a critical role to play in the financial domain. Likewise, automation of multiple processes in agriculture has been a great concern as well as an alarming subject across the world. The population all over the world is growing at a high rate and with this increment, demand for agriculture and its jobs is also growing exponentially. The usual techniques that were used by the farmers are not efficient enough to meet these requirements. Along these lines, new digital techniques are presented. These new strategies satisfy the proper management of agricultural products as well as services so that farmers can make the most of technology to increase their profit rates. AI in the agricultural landscape has initiated a revolutionary change. It has guarded the harvest yield from different declining factors such as environmental changes, over population, dynamic business demands, and food safety issues. By using artificial intelligence we can foster smart farming practices to limit the loss of farmers and give them high returns. Using artificial intelligence platforms, one can collect an enormous amount of information from government and public sites or real-time monitoring and collection of different information is likewise possible by utilizing IoT (Internet of Things) and afterward can be explored with precision to empower the farmers for resolving every one of the issues faced by farmers in the agriculture area. This research is conducted in order to help local farmers everywhere in the world to manage their agriculture practices all the more effectively. The strategy discussed in this paper is leveraging the model of waterfall methodology for planning and creating a system smart enough by performing a sequential cycle that starts with data collection, requirement analysis, plan, coding, and testing and finally implement that system as a whole. This system can also be used to foster ideas to manage normal issues in agriculture information systems, to improve the policy programs, the augmentation, and analysis practices, and to manage data on agriculture. Finally, conclusion about agricultural information systems are discussed and suggestions for additional development of agriculture data systems is presented.
\end{abstract}

Key words: Artificial Intelligence, Content Management System, Agricultural Sector, CMS Optimization

This article is is licensed under a Creative Commons Attribution-NonCommercial 4.0 International License.

Attribution-NonCommercial (CC BY-NC) license lets others remix, tweak, and build upon work non-commercially, and although the new works must also

acknowledge and be non-commercial.

\section{INTRODUCTION}

The total population of the world is expected to grow up to ten billion by 2050, skyrocketing the demand for agriculture in a position of rapid advancement by somewhat around 50 percent as compared to the numbers in 2013 (FAO, 2017). Shockingly, agriculture, however lacking behind in the digital aspect, has witnessed quite a momentum in terms of development and commercialization of technologies used in agricultural scene nowadays. AI has started to assume a significant part in the regular lives of people, expanding the insights and skill to alter the climate (Paruchuri, 2015).

Artificial Intelligence (AI) can be applied cross-disciplinary and it can likewise bring a change in outlook by the way we see farming and agriculture today. AI-powered intelligent systems won't just empower farmers to accomplish more with less, it will also improve the overall quality and ensure quicker go-to-market rates for crops. The present 
innovation and advancement in Artificial Intelligence, Big Data, IoT is turning into a significant driver for providing Digital IT solutions practically in every field and business area. Likewise, it is proposed to utilize these digital solutions supported with Artificial intelligence to inspire the natural surroundings of the crushed farmer community while giving yet another chance to business and business visionaries by presenting brilliant smart systems as a service.

These days, the information technology on the Internet performs commanding jobs and subsequently, people don't need to depend on books and reports, which are generally difficult to access (Ganapathy, 2018). Additionally, distributed information in books and reports frequently neglect to reflect the current status of art, which is fundamental in a cutthroat world. The present circumstance can be addressed by keeping an AI-empowered agricultural information system and making that data accessible on the Internet (Fadziso, 2017). This will help researchers, investors, and all the more important the farmers augment their efficiency as well as their profits. This paper presents the design and development of an intelligent agricultural information system that can a possible answer for the issues faced by the local farmers everywhere in the world - making it more proficient and simpler for them to deal with their crops (Vadlamudi, 2015). This paper additionally features an approach of some of the basic areas shown in Figure 1 where the adoption of AI is probably going to expand manageability in agriculture, and for the local farmers specifically, addresses the tools by which this may happen, and proposes pathways for future.

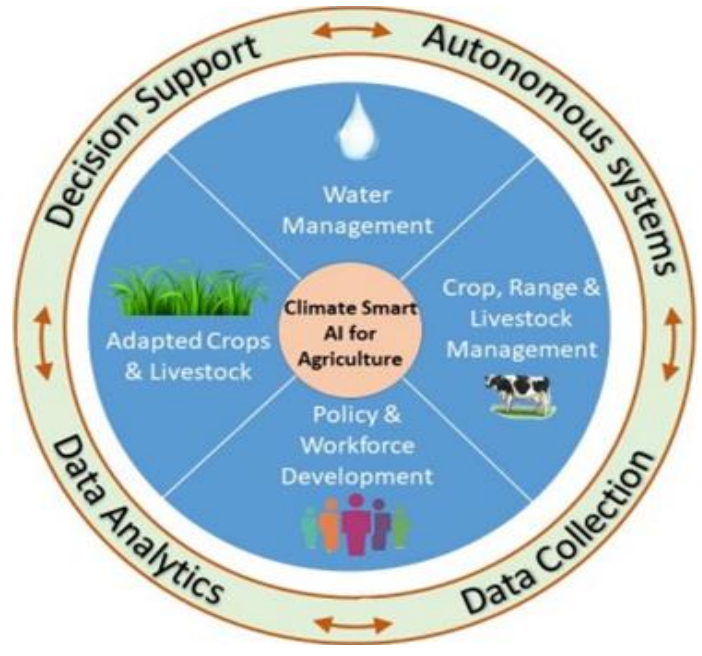

Fig. 1. Critical Areas of AI Application in Agriculture

\section{LITERATURE REVIEW}

One of the early studies (Ganapathy, 2018) unfolded the agricultural systems developed specifically for farmers owning small-scale farms in Malaysia. They placed the role of farmers vital to the system and set their roles as makers, producers, and communicators. Extensive data was being shared among the actors in the system and farmers specifically were dynamic in dispersing creative information and technology.

From that point onward, Ortiz introduced (Fadziso, 2018a) an agricultural information and data management system and explored propagation of connected pest-related data among the research part, augmentation, and producers of potato in Peru. It was discovered that intelligence-based pest management is an innovation required by the farmers. The management of such kinds of information had farmers to understand the innovative standards of intelligent pest management (Vadlamudi, 2017). Then again, in 2006, a study (Ganapathy, 2016) discovered how internet-based social media networks work as key resources for individuals and families in the provincial areas of non-industrial countries and impact their overall access to data and advantages obtained from that research and development processes. They introduced a contextual analysis of the networks in a town and highlighted the actual need that enabled the proficient delivery of services and research involvements at a smaller scale.

As of late, there have been a few research studies about the application of digital data management systems and tools used in agricultural as well as food areas. Silerov ${ }^{`}$ and Lang' (2006) talked about the utilization of the systems as well as the extension of the entries in the agricultural area. The improvement of these digital information systems and implementation having the AI-empowered infrastructure empowers internet access to the data and the successful management and organization of agricultural processes. Also, Kucera and Late' ckov a (2006) brought up the significance of data systems' related to the arrangements w.r.t computer programming and expert systems used in agriculture and food domains. These smart management systems assist with making decisions and add value to the management of agricultural dynamics. 


\section{Research Methodology}

In this segment, the development process and methodology followed by this intelligent information systems important for the agricultural revolution - is demonstrated. The used techniques in this paper are based on a study related to agricultural services and issues faced by farmers in general (Fadziso, 2018b). The information should be collected by obtaining direct information collected from organizations and also from the applicable reports regarding the matter. Verification and confirmation are the next methods that should be carried out for the data processing step.

The steps are performed to figure out the part nature of information as well as the exact data to ensure that information is being used as per system data standard. After that, the step of database development is finished using any relational database. All the verified information is stored in database. The implementation of these information services is the main step to develop an online agriculture community data system. The services offered by this online agricultural information system can be access from anywhere with the help of normal web browsers.

Since the database will require to be updated by skilled professionals at particular research organizations, the system gives simple access to the database for a wide range of data manipulation and control. Security of the data set is ensured by the implementation of a password for updating purposes, which will be given to the main research organizations. This information system also provides the external user the ability to access compressed information in the required data type or format. This can be done for certain crop types for any given years so that farmers can get detailed insights into their past as well as current performance results to modify the costs and different variables of their agricultural system accordingly.

Table 1: Characteristics of an Intelligent Agricultural System Based on AI

\begin{tabular}{|c|l|}
\hline Entity & \multicolumn{1}{|c|}{ Characteristics } \\
\hline Crops Specialization & $\begin{array}{l}\text { Name of the crop } \\
\text { Unique code of the crop }\end{array}$ \\
\hline Product Specialization & Code of the crop \\
& Name of the product \\
& Unique code given to a product \\
\hline Production & Code of a product \\
& Quantity produced \\
& Year of production \\
& The unit cost of the Production \\
\hline Institute Description & Unique code given to a crop \\
& Unique code given to an institute \\
& Name of institute \\
& Location of the institute \\
\hline Research Type Description & Unique code given to an institute \\
& Description of research type \\
& Unique code given to a research type \\
\hline Research Description & Unique code given to a research type \\
& Description of research \\
& Achievements of research \\
& Annual output of the research \\
& Year of the research \\
\hline
\end{tabular}

\section{Data Oriented Agriculture - Agriculture 4.0}

This phenomenon of new way of thinking completely based on the agricultural information has been presented with a few different terminologies and names, and was introduced when traditional information management was combined to the existing ideology of agriculture focused around precision to improve the accuracy of processes (CEMA, 2019). Accordingly, the idea of Agriculture 4.0 depends on agriculture standards with farmers using information mediums that produce information with regards to their farms, and afterwards be trained in a way that make them appropriate, strategically sound, and able to make operational choices. In the most cases, farmers usually themselves go to their fields for the monitoring and analysis of the situation of the fields and then make decisions on that collected insight. This methodology is no longer maintainable as, due to different reasons, few fields are very spread-out to even think about being effectively monitored according to the criteria as follows: efficiency, ecological, and easy accessibility. 
Intelligent information systems inside the setting of intelligent farming are starting to provide viable methods for smart farming (Ganapathy, 2017). Additionally, regardless of certain farmers making some experience collected after huge and long periods of work, technology may outperform them and provide a systematic approach to identify the potential issues that are hard to see by visual investigation on manual visits. However, the willingness of embracing modern devices in agriculture shown by new-day farmers display a more uplifting perspective than the previous ones, as the young ones can support their not-so-big involvement with the field with the latest technology and smart tools giving important bits of information through smart systems. A few solutions, for instance, must be set up to help renewal, access to the initial investment, advances, consultation, and learning (European Commission, 2012). A renewal in an agricultural advancement setting goes past a decrease in the normal time of traditional farmers and it is also about engaging another lot of immensely talented and new farmers to acquire the advantages of emerging technology (Artificial Intelligence, Internet of Things, etc.) to back the manageable practices adopted by farmers (Ganapathy, 2017). Hence, this idea suggests that new farmers should change the current land to modernized and competitive farms intended to keep up suitable agricultural production for improving the sustainability of agricultural food chain since having the cutting-edge innovations and modern practices, farmers will be able to change the space for good.

\section{EVOLUTION OF AGRICULTURE 5.0}

Huge engineering challenges normally outgrow large solutions through game-changing innovations, and evolution of agriculture from agriculture 4.0 to agriculture 5.0 is likely the one for 21st Century. The idea suggests that farmers must follow standards and use hardware that includes automated processes and autonomous systems that enable a smart decision-making process. Hence, it infers the utilization of drones, robots and a few other types of AI (Fadziso, 2018a). In usual cases, farms have required numerous workers, mostly during the seasons, to collect harvests and keep the farms running. Be that as it may, the world is moving away from being an agricultural landscape with a lot of people living on farms and in urban communities, hence, the farms have been fronting the risk of a labor force shortage.

A potential answer to solving this challenge of lack of laborers is developing robots that are specifically designed for agricultural activities having AI infrastructure and skills. Agricultural robots expand the labor workforce and can harvest crops very much quicker and at a higher volume than human workers. In spite of the fact that there are multiple cases wherein agricultural robots are as quick as expected as humans, still the revolutionaries are currently creating automated framework and help farmers with monotonous activities in the fields, emphasizing them to acknowledge and adapt to the new idea of Agriculture 5.0.

Having discussed previously, autonomous applications in agriculture are developing dramatically that offer highly promising alternatives for farming to assist with workforce shortage and decreasing productivity. In any case, as with most technologies, there are significant challenges to adapt to these evolving technologies at current stages. These methods are very costly for majority of the farmers to apply, especially those farmers having small farms since financial aspects make them less beneficial. Nonetheless, the expense of this reduces with the new advancements being introduced each day. Autonomous agricultural activities will definitely be carried out later on to achieve higher production levels. The idea of robotics in agriculture was presented to face the challenges and fulfill the need for significant profits for farmers without having to go and monitor their fields as well as inventory every single time.

\section{Applications of Al in InTELLIGent Agriculture SyStem}

In the hugely rural and agricultural regions, the difficulties and opportunities are enhanced as agricultural production systems find it hard to adapt to fast changes in water availability, climate change, and labor workforce unavailability. In this way, there is a need to adjust to this development locally and provincially to provide management techniques to help farmers and their activities and smart farming as a whole. Creative solutions can be presented through the application of artificial intelligence (AI) based systems in agriculture to address these difficulties.

\section{Adaptive Management of Systems}

Labor unavailability and environmental vulnerability drive loss of productive effectiveness and increase the unexpected expenses in the management of farms, putting stress on already smaller profits and increasing production loss. In spite of the fact that $\mathrm{AI}$ is starting to be utilized in agricultural management, it lacks in the area of precision farming. Adapting to these developments in AI and creating innovative solutions for management and livestock production will be important for the consistent success and manageability of both farms and the general resources on which they depend.

\section{Agricultural Data Integration}

The formation of an overall System of Systems (SoS) will require consistent reconciliation and information management from collected sources including climate, water, soil, environment, vegetation, animal health, 
phylogenetics, satellite pictures, financial, demographic, and labor, etc. To do as such, new integration components should be developed that use advanced ontologies and data storage tools, distribution through cloud computing frameworks, and various other tools (Paruchuri, 2017). The integration process must be perceptive of information standards inside different research networks, and the protection and security needs of the major agents.

\section{Consistent Automation and Control}

Autonomous robots, drones, and other detecting tools can obtain constant data that can be used to monitor crop development, identify disease and pests, and assess water levels, and survey animal health from time to time. If an activity is required, robots specialized for specific tasks can successfully come into play. Successfully coupling automation with AI means identifying the factors to be checked, deciding the kind of sensor(s) to be utilized i.e. automated pictures taken by robots, IR sensors integrated into robots, identifying activities that can adaptively be addressed i.e. apply treatment, extra watering, crop harvesting, supply feed, and creating mechanical systems trained to do automatically performing the assigned activities (Fadziso, 2018c).

\section{Picture-based Insight Generation}

Precision Farming is quite possibly the most talked-about area in agriculture today. Drone-based pictures can help in top-to-bottom field analysis, crop tracking, field research, etc. Computer Vision innovation, IoT, and robot information can be integrated to ensure quick activities by farmers. Data from drone pictures can produce alerts to speed up the precision farming process (Ganapathy \& Neogy, 2017). Different organizations are implementing the IBM Watson IoT Platform and the Visual Recognition APIs in business drones for image analysis progressively. Likewise, this can be a game-changing advancement for real-time data collection and later on utilize that data for smart decision making.

\section{Role of Automation in Agricultural Management Systems}

Any area needs to develop with time. The agriculture area needed to adjust to the advancements and developments which went along in the automation field. The area approached with an expanding research space of embedded intelligence (EI). Embedded intelligence in the agriculture area includes smart farming, efficient crop management, smart water system, and smart greenhouses (Ganapathy, 2015). It is fundamental for a country to remember these developing innovations for agriculture area for development of a country as numerous areas are dependent on agriculture. Additionally, researchers of various studies have shown a Technology Roadmap (TRM) which briefly explains the second thoughts in regards to the areas of agriculture referenced above (smart farming, smart water system, and so on.).

Contemplating the social and financial imperativeness of agriculture, experts developed a system that anticipated grape disease in its earlier stage. Any disease in the grape plant was seen solely after it was infected and this had a significant weakening impact on the overall grape plantation. The system leveraged different sensors like temperature sensors, leaf wetness sensors, and humidity sensors in the grape plantation.

These sensors send the information detected to the database in a wireless server that is connected to the sensors. Solution of Wireless System Network (WSN) in any field needs to fulfill certain rules and global standards. This algorithm is designed to prepare the normal information collected by the sensors and report any deviation in temperature, humidity, or leaf wetness which can bring about the grape disease to farmers through SMS.

To improve effectiveness, usefulness, and to minimize the inference, time and cost of humans, Internet of Things must be leveraged in order to achieve a greater application of automation in the agriculture area. IoT is the network of various devices to transfer data without human contribution. Thus, to acquire high proficiency, IoT works in integration with agriculture to enable automated and smart farming.

The featuring highlights of this methodology incorporate smart GPS-based remotely controlled robots to perform tasks like; weeding, spraying, humidity detecting, bird and animal startling, keeping alertness, and so on. Also, it includes a smart water system with intelligent control based on continuous field data. Thirdly, smart inventory management incorporates; temperature support, humidity maintenance, and theft recognition in the warehouse. Controlling this load of activities will be through any remote smart gadget or computer associated with the Internet and the tasks will be performed by connected sensors.

\section{Challenges in Al-based Agricultural Systems}

Intelligent/expert systems are devices for agricultural management since they can give site-explicit, integrated, and connected tools. In spite of the fact that AI has made some striking improvement in the agricultural area lately, a lot more should be done to improve agricultural exercises using AI as there are numerous limitations to its execution. 


\section{Response Time and Accuracy}

A significant quality of an intelligent or expert system is its capacity to execute tasks precisely in a brief time frame. The majority of the systems miss the mark either according to the time or precision, or even both. A system delay influences a user's choice of task procedure. People looking to limit effort and expand precision can choose among the following three methodologies: automated performance, pacing, and monitoring (Ganapathy, 2016).

\section{Huge Data Required}

The strength of an expert system is likewise estimated on the volume of information. A constant AI system needs to have a huge volume of information. The system should filter out a significant part of the coming information. In-depth information on the task of the system is needed from a domain master and without a doubt, extremely significant information should be utilized to improve the system's response time and accuracy. The advancement of an agricultural expert system requires the combined effort of experts from numerous fields of agriculture and should be created with the participation of the producers who will use them.

\section{Adaptability}

Adaptability is a solid characteristic of any strong AI system. It is seen that much advancement has been made in applying AI methods to specific tasks, yet the significant subject at the main edge of the AI-based technologies appears to be the interfacing of the subsystems into a coordinated environment (Neogy \& Paruchuri, 2014). This requires adaptability of the actual subsystems. It should likewise have extensive abilities to cater to more useful information from the domain expert.

\section{VARIOUs Models for Agricultural SERVICES}

\section{Intelligent Chatbots}

At present, AI-controlled chatbots (virtual agents) are utilized in retail, travel, media, and various other areas. In any case, agriculture could likewise use this innovation by helping farmers with answers and suggestions on specific issues. This service lets the farmers get their questions addressed through smart voice talk in their local languages. The chatbot engine is driven by both supervise and reinforced AI algorithms for persistent and context-specific learning. Subsequently, the chatbot answers to the majority of the non-specific queries before it allows human operator intervention for any questions that are exclusive.

\section{Agri-E-Calculator}

The agri-e-calculator as an application assist the farmers with picking the most appropriate crop make affordable decision based on some important factors. Farmers can utilize smart e-calculators and easily choose most ideal crop develop over the most affordable area within the farm. Then, at that point, any remaining required information sources are consequently identified by the e-calculator and provide the assessment. This result gives helpful information on the assessment of fertilizers cost/amount, water, seeds, and development equipment cost to make better financial choices (Vadlamudi, 2016).

\section{Crop Care Service}

The crop care model traverses directly from the planting of seeds as a start point till the phase of harvesting as the end goal. The complex organized information obtained from IoT sensors from the fields is examined alongside the information gathered from bits of information alongside domain expert reviews anywhere required through Artificial Intelligence strategies (Fadziso, 2018a). After the examination of complete information, the general thing to do is to infer out of PID (Proportional Integral and Differential) regulator system. Appropriately, the right measures are made aware of the farmers on their smartphones to prioritize the activity based on seriousness and direness to follow up on.

\section{Price Prediction and Market Analysis}

This model assists with providing farmers with right analysis and protect them from variance and the risks of loss in value. Because of the factual information gathered, a prescient price and demand data is given to the farmers throughout the total harvest process. What's more, farmers can design effectively possible solutions to deliver products to market.

\section{CONCLUSION}

The agricultural business area faces different difficulties like the absence of successful water systems, problems because of crop stature, and dynamic environmental conditions. Be that as it may, this execution can be enhanced with innovation and hence the issues can be settled. These problem are to be addressed with various procedures backed by 
artificial intelligence like remote sensors, commerce management systems, and autonomous water system. Challenges faced by farmers were mostly due to the traditional methods overshadowing the huge scales of yields being gone while the harvesting cycle. These autonomous robots not only enhance the effectiveness, they additionally lessen requirements for insecticides. Other than that, farmers will be able to spray insecticides viably with the help of IoTbased robots and intelligent sensors, and crop analysis is no more a hassle. First off, deficits of resources and jobs must be solved with artificial intelligence prowess in agricultural issues. In customary methodologies, a huge measure of effort and time was needed for to get the required - triggering a monotonous way of manual testing. By the assistance of different methodologies and models analyzed in this paper, fast and efficient high agricultural processes would happen with the potential gain of flexible and worthwhile advancement, on-demand access to data, and spatial objectives. So, the future looks bright for the agricultural landscape if it adapts to the technology pretty well and keeps up.

\section{REFERENCES}

CEMA. Digital Farming: What Does It Really Mean? Available online: http://www.cemaagri.org/publication/digital-farming-what-does-itreally-mean (accessed on 17 September 2019).

European Commission. (2012). Generational Renewal in EU Agriculture: Statistical Background; DG Agriculture Rural Development: Economic analysis of EU agriculture unit: Brussels, Belgium, pp. 1-10.

Fadziso, T. (2017). Understanding the Unending Learning Language Technique. Asian Journal of Humanity, Art and Literature, 4(2), 141-146. https://doi.org/10.18034/ajhal.v4i2.560

Fadziso, T. (2018a). Internet of Things in Agriculture for Smart Farming. Malaysian Journal of Medical and Biological Research, 5(2), 147-156. https://doi.org/10.18034/mjmbr.v5i2.565

Fadziso, T. (2018b). Space Computation Sciences Leveraging Cloud Computing, Artificial Intelligence, and Advanced Analytics to Power Innovation: A Review Report. Asia Pacific Journal of Energy and Environment, 5(2), 89-90. https://doi.org/10.18034/apjee.v5i2.519

Fadziso, T. (2018c). The Impact of Artificial Intelligence on Innovation. Global Disclosure of Economics and Business, 7(2), 81-88. https://doi.org/10.18034/gdeb.v7i2.515

FAO. (2017). Food and Agriculture Organization of the United Nations, 2017. THE STATE OF FOOD AND AGRICULTURE LEVERAGING FOOD SYSTEMS FOR INCLUSIVE RURAL TRANSFORMATION. 978-92-5109873-8pp. 1-181

Ganapathy, A. (2015). AI Fitness Checks, Maintenance and Monitoring on Systems Managing Content \& Data: A Study on CMS World. Malaysian Journal of Medical and Biological Research,2(2), $113-118$. https://doi.org/10.18034/mjmbr.v2i2.553

Ganapathy, A. (2016). Blockchain Technology Use on Transactions of Crypto Currency with Machinery \& Electronic Goods. American Journal of Trade and Policy, 3(3), 115-120. https://doi.org/10.18034/ajtp.v3i3.552

Ganapathy, A. (2017). Friendly URLs in the CMS and Power of Global Ranking with Crawlers with Added Security. Engineering International, 5(2), 87-96. https://doi.org/10.18034/ei.v5i2.541

Ganapathy, A. (2018). Cascading Cache Layer in Content Management System. Asian Business Review, 8(3), Art. \#24, pp. 177-182. https://doi.org/10.18034/abr.v8i3.542

Ganapathy, A., \& Neogy, T. K. (2017). Artificial Intelligence Price Emulator: A Study on Cryptocurrency. Global Disclosure of Economics and Business, 6(2), 115-122. https://doi.org/10.18034/gdeb.v6i2.558

Kucera, M., and L`ate' ckov`a, A. (2006). Information and knowledge' systems in the operation of agricultural and food-processing enterprises. Agricultural Economics - Czech, 52, 353-357.

Neogy, T. K., \& Paruchuri, H. (2014). Machine Learning as a New Search Engine Interface: An Overview. Engineering International, 2(2), 103-112. https://doi.org/10.18034/ei.v2i2.539

Paruchuri, H. (2015). Application of Artificial Neural Network to ANPR: An Overview. ABC Journal of Advanced Research, 4(2), 143-152. https://doi.org/10.18034/abcjar.v4i2.549

Paruchuri, H. (2017). Credit Card Fraud Detection using Machine Learning: A Systematic Literature Review. ABC Journal of Advanced Research, 6(2), 113-120. https://doi.org/10.18034/abcjar.v6i2.547

Silerov`a, E., and Lang, K. (2006). Information systems - tool for`changing our future. Agricultural Economics - Czech, 52, 447-450.

Vadlamudi, S. (2015). Enabling Trustworthiness in Artificial Intelligence - A Detailed Discussion. Engineering International, 3(2), 105-114. https:/ / doi.org/10.18034/ei.v3i2.519 
Vadlamudi, S. (2016). What Impact does Internet of Things have on Project Management in Project based Firms?. Asian Business Review, 6(3), 179-186. https:// doi.org/10.18034/abr.v6i3.520

Vadlamudi, S. (2017). Stock Market Prediction using Machine Learning: A Systematic Literature Review. American Journal of Trade and Policy, 4(3), 123-128. https://doi.org/10.18034/ajtp.v4i3.521

$$
--0 \text {-- }
$$

